\title{
Atomic Oxygen Treatment as a Method of Recovering Smoke Damaged Paintings
}

Sharon K. Rutledge and Bruce A. Banks

Lewis Research Center, Cleveland, Ohio

Mark Forkapa, Thomas Stueber, and Edward Sechkar

NYMA, Inc., Brook Park, Ohio

Kevin Malinowski

Cleveland State University, Cleveland, Ohio

Prepared for the

American Institute for Conservation of Historic Artwork sponsored by the American Institute for Conservation

Washington, DC, June 3-7, 1998

National Aeronautics and

Space Administration

Lewis Research Center 


\section{Acknowledgments}

The authors would like to thank Mr. Richard Moore of Bonfoey Cornpany in Cleveland Ohio, and Mr. Kenneth Bé of the Cleveland Museum of Art for donating some extreme fire damaged paintings for our testing, and also providing very helpful comments, discussion and advice.

Trade names or manufacturers' names are used in this report for identification only. This usage does not ronstitute an official endorsement, either expressed or implied, by the National Aeronautics and Space Admiristration.

$\begin{array}{lr} & \text { Available from } \\ \text { NASA Center for Aerospace Information } & \text { National Technical Information Service } \\ 7121 \text { Standard Drive } & 5287 \text { Port Royal Road } \\ \text { Hanover, MD 21076 } & \text { Springfield, VA 22100 } \\ \text { Price Code: A03 } & \text { Price Code: A03 }\end{array}$




\title{
ATOMIC OXYGEN TREATMENT AS A METHOD OF RECOVERING SMOKE DAMAGED PAINTINGS
}

\author{
Sharon K. Rutledge and Bruce A. Banks \\ National Aeronautics and Space Administration \\ Lewis Research Center \\ Cleveland, Ohio 44135 \\ Mark Forkapa, Thomas Stueber, and Edward Sechkar \\ NYMA Inc. \\ Brook Park, Ohio 44142 \\ Kevin Malinowski \\ Cleveland State University \\ Cleveland, Ohio 44115
}

\begin{abstract}
SUMMARY
Smoke damage, as a result of a fire, can be difficult to remove from some types of painting media without causing swelling, leaching or pigment movement or removal. A noncontact technique has been developed which can remove soot from the surface of a painting by use of a gently flowing gas containing atomic oxygen. The atomic oxygen chemically reacts with the soot on the surface creating gasses such as carbon monoxide and carbon dioxide which can be removed through the use of an exhaust system. The reaction is limited to the surface so that the process can be timed to stop when the paint layer is reached. Atomic oxygen is a primary component of the low Earth orbital environment, but can be generated on Earth through various methods. This paper will discuss the results of atomic oxygen treatment of soot exposed acrylic gesso, ink on paper, and a varnished oil painting. Reflectance measurements were used to characterize the surfaces before and after treatment.
\end{abstract}

\subsection{INTRODUCTION}

Fires in museums and public buildings can result in complete destruction of artwork on display or can soil the artwork with accumulated soot to an extent to which it can no longer be used for study or be enjoyed by the public. In situations where the surface has not undergone extensive charring or melting, restoration attempts can be made. However, soot deposits can be very difficult to remove from some types of painted surfaces, particularly those where the paint is fragile or flaking or where damage to the top surface of the paint binder has occurred. Restoration typically involves the use of organic solvents to clean the surface (ref. 1). But these solvents may cause swelling or leaching of the paint layers (ref. 2). Immersion of the surface or swabbing during solvent cleaning may also cause pigment movement or removal through mechanical contact especially if the fire damage extends into the paint binder.

A noncontact technique of removing organic deposits from surfaces was developed out of NASA research on the effect of oxygen atoms on various materials. Atomic oxygen is present in the atmosphere surrounding the Earth at altitudes where satellites typically orbit. It has been shown to react chemically with surface coatings or deposits that contain carbon (refs. 3 to 4). In the reaction, the carbon is converted to carbon monoxide and some carbon dioxide. Water vapor is also a byproduct of the reaction if the surface contains carbon-hydrogen bonds. As a result of the need to study this reaction, facilities have been developed on Earth which can produce atomic oxygen for material exposure and testing (ref. 5). Radio frequency, microwave or electron bombardment can be used to split molecular oxygen into atomic oxygen. These atoms at low energy can be directed at a surface, like a gentle shower, or allowed to surround the object, as in a bath. The exposure is performed in a vacuum chamber where pressures typically range from 0.001 to 100 millitorr depending on the technique used. Because it is a dry process, there is no risk of leaching or swelling. In addition, the atomic oxygen reaction is confined to the surface which minimizes the risk to the underlying paint or canvas. 
The technique was demonstrated to be effective in cleaning soot from small sample sections of canvas, acrylic gesso, and an unvarnished oil painting (ref. 6). The process, which has been patented by NASA, is not intended to be a replacement for conventional techniques, but to be an additional tool for use where conventional techniques may not be effective (ref. 7). However, for the technique to be practical as a restoration tool, it is necessary to demonstrate that atomic oxygen can be generated uniformly over a large area and that full size paintings can be treated.

\subsection{PROCEDURE}

\subsection{Test Articles}

Acrylic gesso on a stretcher frame (approximately $90 \times 120 \mathrm{~cm}$ ) purchased from Michael's Arts and Crafts was used to perform the initial checkout of the large area atomic oxygen treatment system. Streaks of soot from a wax candle flame were made on both the paintable surface and on the back of the canvas for test purposes.

Two full size pieces were also provided for testing. The first was a Roy Lichtenstein ink on paper untitled abstract from 1950 . The work, which was owned by a private collector, had been heavily smoke damaged and partially thermally decomposed in a fire. The McKay Lodge Fine Arts Conservation Lab in Oberlin, Ohio had previously tried float washing in alkaline water $(8.0 \mathrm{pH}$ ammonium hydroxide) and immersion in a sodium borohydride solution $(<1$ percent $v / v)$ but these processes had a minimal effect on the appearance of the piece. Bonfoey Company in Cleveland, Ohio supplied the Lichtenstein for atomic oxygen treatment.

The second piece that was donated for testing was a copy of the Raphael painting "Madonna of the Chair." The copy was painted by Bianchini of the Studio Viale Petrarca in Firenze Italy for St. Albans church in Cleveland. An arson fire at the church in the 1980's severely damaged several painting:. The paintings were given to the Cleveland Museum of Art for restoration. The Madonna painting, which was a varnished oil painting, was heavily smoke damaged and partially charred. It was believed that the damage extended through the varnish into the paint binder. A section of the painting was initially treated at the museum with acetone, then with methylene chloride and some additional solvents. Some of the soot and varnish were removed by these techniques, however, the surface was still very dark and features were difficult to distinguish. The Madonna painting was considered to not be able to be salvaged and was donated for testing of the atomic oxygen treatment process.

\subsection{Atomic Oxygen Cleaning}

Cleaning of the test articles was performed in a large vacuum chamber that could hold a painting roughly 1.5 by $2.1 \mathrm{~m}$ in size on its stretcher frame. The size was determined partly on a vailability of a vacuum chamber, and also on the ability to clean a reasonable number of painting sizes. Based on the size distribution of 1008 cataloged paintings from the National Gallery of Art, this size would accommodate roughly 85 percent of them.

The vacuum in the chamber is provided by conventional vacuum pe mps with pressures during treatment ranging from 1 to 5 millitorr. Two large aluminum parallel plates inside the chamber produce the plasma. One plate is connected to an RF power supply operating at roughly $400 \mathrm{~W}$. The second plate is at ground potential. The ground plate has several bolts attached to it from which test articles to be cleaned can be suspended either by fine wire attached to the frame of the test article or by acting as a support for the stretcher frame. The articles are hung so that the ground plate is in contact with the back of the piece, thereby shieldirg the back side from the atomic oxygen during cleaning. A controlled entry of air into the chamber at rates betwien 50 and 280 standard $\mathrm{cm}^{3} / \mathrm{min}$ provides the source of the plasma. Radio frequency oscillation of electrons between the two plates produces splitting of the oxygen in the air into atomic oxygen. The dissociation of the air into atomic species creates a pink colored glow between the plates. The nitrogen in the air has been found not to have ar effect on carbon removal and acts as an inert gas for these treatment exposures. An automated timer and controller on the system allows the cleaning to proceed over a desired timeframe unattended and will turn the system off if a loss in vacuum, water cooling to the pumps and power supply or drop in plasma intensity is detected. 


\subsection{Analysis}

A quartz halogen microscope light set at full intensity, producing light at a wavelength on the average of $900 \mathrm{~nm}$, was mounted on an aluminum beam so that the light could hit the surface of a painting at roughly a 45 degree angle. This setup was used to monitor diffuse reflectance from selected sections of the test articles at various intervals during the cleaning process with a detector placed near the light source. The equipment was placed in a dark room to minimize effects from stray light. A magnesium oxide coated glass slide was used to calibrate the detector to eliminate drifts in the response over time. The area that could be illuminated was approximately $1.91 \mathrm{~cm}$ diameter so it was necessary to select areas from the test articles that were both uniform over this size range and had potential for changing the most (largest contrast) during the cleaning process. In this way, the progress of the cleaning could be measured by looking for a leveling off of the reflected light signal which indicated that no further change was taking place.

\subsection{RESULTS AND DISCUSSION}

\subsection{Cleaning of Smoke Streaks from Gesso}

The first test of the large area treatment capability was performed with gesso on a stretcher frame that had been streaked on the front and back with soot from a wax candle flame. Figure 1(a) shows the front side of the gesso with smoke streaks prior to atomic oxygen exposure. After approximately $14 \mathrm{hr}$ of cleaning in atomic oxygen, the smoke streaks were completely removed from the surface as shown in figure $1(\mathrm{~b})$. The rear of the canvas remained untouched as shown by the comparable photos of the back side of the gesso shown in figures 2(a) and (b). This demonstrated the ability of the system to uniformly remove soot over a large area while protecting the back side from being overcleaned. Too long of an exposure of the canvas could cause removal of the sizing and weaken it if it were not shielded from atomic oxygen during cleaning.

\subsection{Cleaning of Roy Lichtenstein Ink on Paper}

The Lichtenstein proved to be a very difficult first test subject. Several things about the abstract created a challenge. The media was ink, which has a carbon pigment, so it was unknown whether the cleaning process could preferentially remove the soot without also removing the ink. Also, the paper appeared to have thermal damage.

Therefore, it would be difficult to remove char from the paper without weakening it.

First, it was necessary to determine whether soot could be removed more quickly than ink would be lost from the surface of the paper. In order to test this, a $1.9 \mathrm{~cm}$ wide brush was used to apply stripes of various types of ink and watercolor onto the surface of watercolor paper. A wax candle flame was then used to apply a wide soot streak across the paper. The reflectance of light provided by a quartz halogen lamp was then monitored from each type of media and the candle soot at various intervals during the atomic oxygen cleaning process. The resulting graph shown in figure 3 indicates that the candle soot is removed much more rapidly than the media tested and is quickly brought back to near the original reflectance of the paper, which is shown by the dashed and dotted reference line. All of the media tested experienced some loss of material after about an hour of cleaning, except for the Shellac filled ink which appeared to be very durable. This ink probably contains inorganic material in the pigment which would greatly slow down the loss of the carbon in the ink due to reaction with atomic oxygen.

Because the ink was a little more resistant to oxidation than first believed, it was decided to try to expose a corner of the Lichtenstein to atomic oxygen in order to determine if the paper could be lightened, and whether the type of media used for this piece could be cleaned without being removed. The Lichtenstein was masked with a polymer sheet roughly $0.005 \mathrm{~cm}$ thick by laying the polymer over the piece so that an edge of the piece was exposed and then taping the polymer down to the matting around the piece. An initial cleaning of approximately 12 min showed some lightening of the surface without affecting the ink areas. The mask was then removed and the entire surface was cleaned for intervals of 12,30 and $60 \mathrm{~min}$. At this point, cleaning was stopped because it did not appear that the paper background could be lightened further without loss of some of the thinner ink features. At the request of the conservator, we did mask off the bulk of the ink areas and tried to further lighten the paper in the upper left comer of 
the piece using a polymer mask with the edges rolled up to create a graduated cleaning that would prevent sharp cleaning lines from appearing on the surface. Figure 4 shows the reflected light data from two areas on the paper being cleaned, one with a light smoke exposure and the other which was much darker. After a total cleaning exposure of about $300 \mathrm{~min}$, there was no noticeable improvement in the piece. The area still had a light yellow cast, which was most likely due to thermal damage of the paper. Figure 5 contains photos of the Lichtenstein before and after cleaning with atomic oxygen.

Some of the important lessons learned from the cleaning of this piece were that areas could be successfully masked for cleaning without creating cleaning lines, and that it was possible to carefully clean pieces that have ink on the surface. This was due to the fact that the soot appeared to be removed more readily than the ink and cleaning could be performed slowly and stopped at any point at the discretion of the conservator.

\subsection{Cleaning of Madonna of the Charr Painting}

The "Madonna of the Chair" painting posed a different type of challenge. This piece had experienced very heavy smoke damage and some thermal decomposition. Areas of the varnish were charred in appearance and it appeared that the damage may have progressed into the surface of the pairt binder.

Prior to treatment, several areas were chosen on the painting for reflected light measurement at selected intervals during cleaning in order to monitor the treatment process. The upper and lower background of the painting were selected because these should remain relatively dark and approximately the same during cleaning. The Madonna's garment was selected because it should clean to a higher level of reflectance than the background. The greatest contrast between the original and the treated piece was expected to be the reflected light from the infant's leg. Cleaning would be considered complete when a change in the diffusely reflected light from these surfaces would no longer be measurable.

Figure 6 contains the reflected light data for the Madonna painting as a function of cleaning time. After approximately $350 \mathrm{hr}$, the majority of the darkened varnish was removed from the surface. There were still some thin streaks on the surface. The majority of these were removed after approximately $600 \mathrm{hr}$ of treatment. Treatment was allowed to progress part of the way into the binder in order to remove the smoke damaged portion as much as possible. After cleaning, the surface was pigment rich and it was necessary to apply a material as a thin mist spray to replace the binder and provide some support for the pigment. The surface was mist sprayed with Damar varnish to avoid any movement of pigment that would occur by using a brush on the surface. Several coats of Grumbacher aerosol Damar were applied to the surface until the gloss was restored, then a brush was used to apply a thicker coating of Winsor \& Newton Damar varnish over the surface. Figure 7 contains photographs of the Madonna painting as received (fig. 7(a)) and after cleaning with atomic oxygen and application of varnish (fig. 7(b)). The details of the painting are now clearly visible. The color restoration was very good, except that there was a slight yellow cast or antique tone which was due to the varnish used. A conservator would be able to make a much better selection of a material as a spray-on replacement for the binder which could provide a better match for the original.

Removal of all of the varnish on the surface, and the top layer of bi inder material is not necessary in all cases. Some fire damaged works, however, may require extreme cleaning to be able to restore them to near their original state so that they can be enjoyed again. From treatment of this painting it was determined that atomic oxygen cleaning can, by longer exposure times, safely remove thermally damaged varnish and paint binder from the surface of an oil painting. Further testing of this cleaning technique is being conducted to determine its effectiveness for cleaning smoke damaged acrylic paintings and watercolors.

\subsection{CONCLUSIONS}

Atomic oxygen treatment has been shown to be able to effectively remove smoke damage uniformly on full size paintings. Masking techniques can also be used to treat one area more extensively without leaving visible cleaning lines. Difficult media such as ink on paper can be carefully cleaned to some extent using atomic oxygen. Although some inks appear to be less readily removed than soot, care should still ye exercised in balancing removal of soot with removal of the ink. This would also be true for organic based paint pigments. Treatment can progress at the discretion of the conservator from light surface cleaning, to more extensive removal of fire damage. The process is not intended to be a replacement for conventional techniques, but as an additional conservation tool in applications where conventional techniques have not been effective. 


\subsection{REFERENCES}

1. de la Rie, E.R., Analytical Chemistry, 61(21), November 1, 1989.

2. Feller, R.L., Stolow, N., Jones, E.H., 1985, On Picture Varnishes and Their Solvents, National Gallery of Art: Washington D.C., pp. 47-116.

3. Banks, B.A. et al., NASA/SDIO Space Environmental Effects on Materials Workshop, 1988, NASA CP-3035, pp. 197-239.

4. Banks, B.A. and Rutledge, S.K., Proceedings of the Fourth European Symposium on Spacecraft Materials in the Space Environment, CERT, Toulouse, France, Sept. 6-9, 1988, pp. 371-392.

5. Banks, B.A. et al., Proceedings of the $18^{\text {th }}$ Annual Symposium on Applied Vacuum Science and Technology, 1989, NASA TM-101971.

6. Rutledge, S.K., and Banks, B.A. Atomic Oxygen Treatment Technique for Removal of Smoke Damage from Paintings, 1996, NASA TM107403.
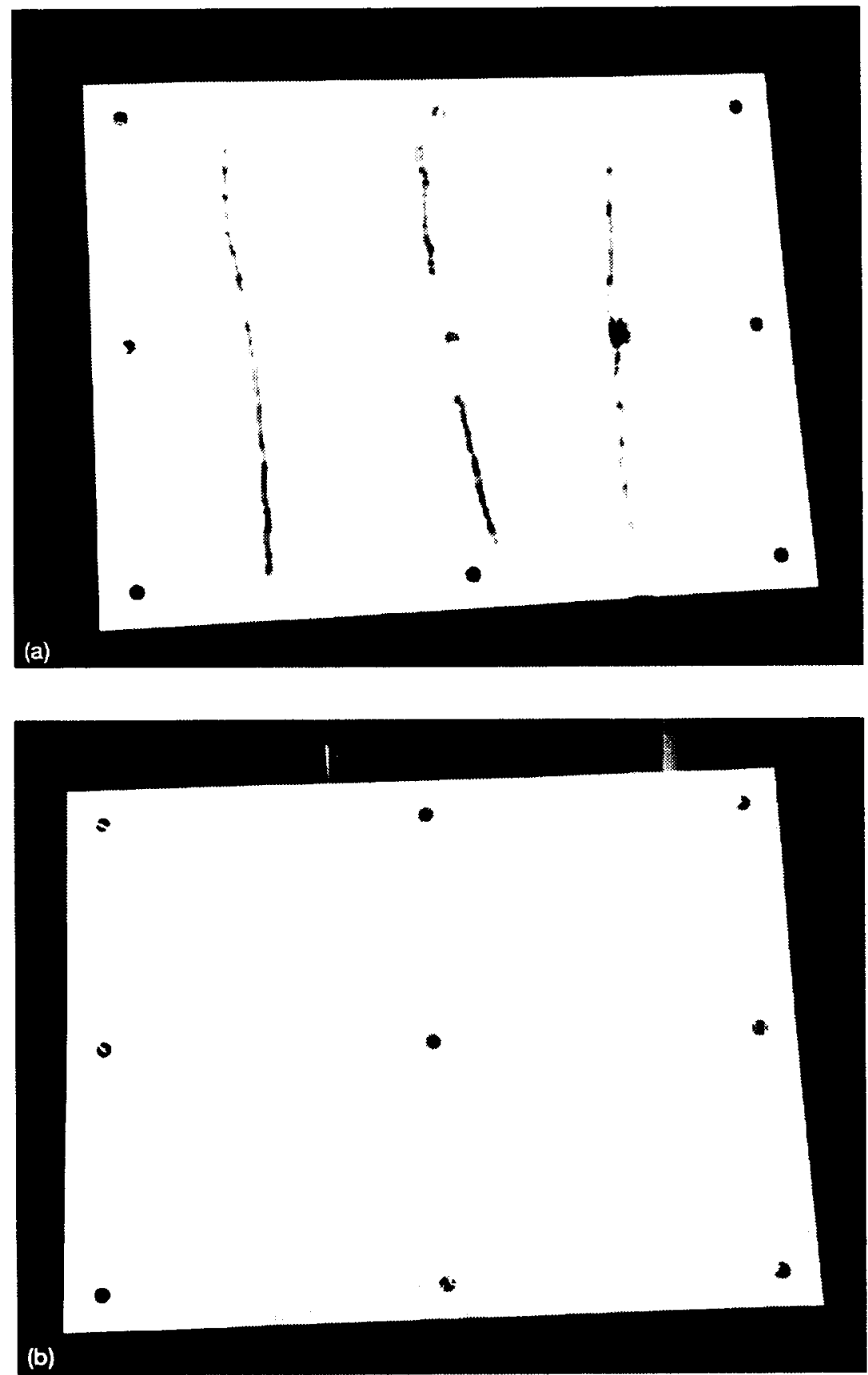

Figure 1.-Gesso surface showing candle soot streaks prior to (a) and after (b) cleaning with atomic oxygen. (Small circles on the canvas were polymer disks used to measure atomic oxygen arrival). 

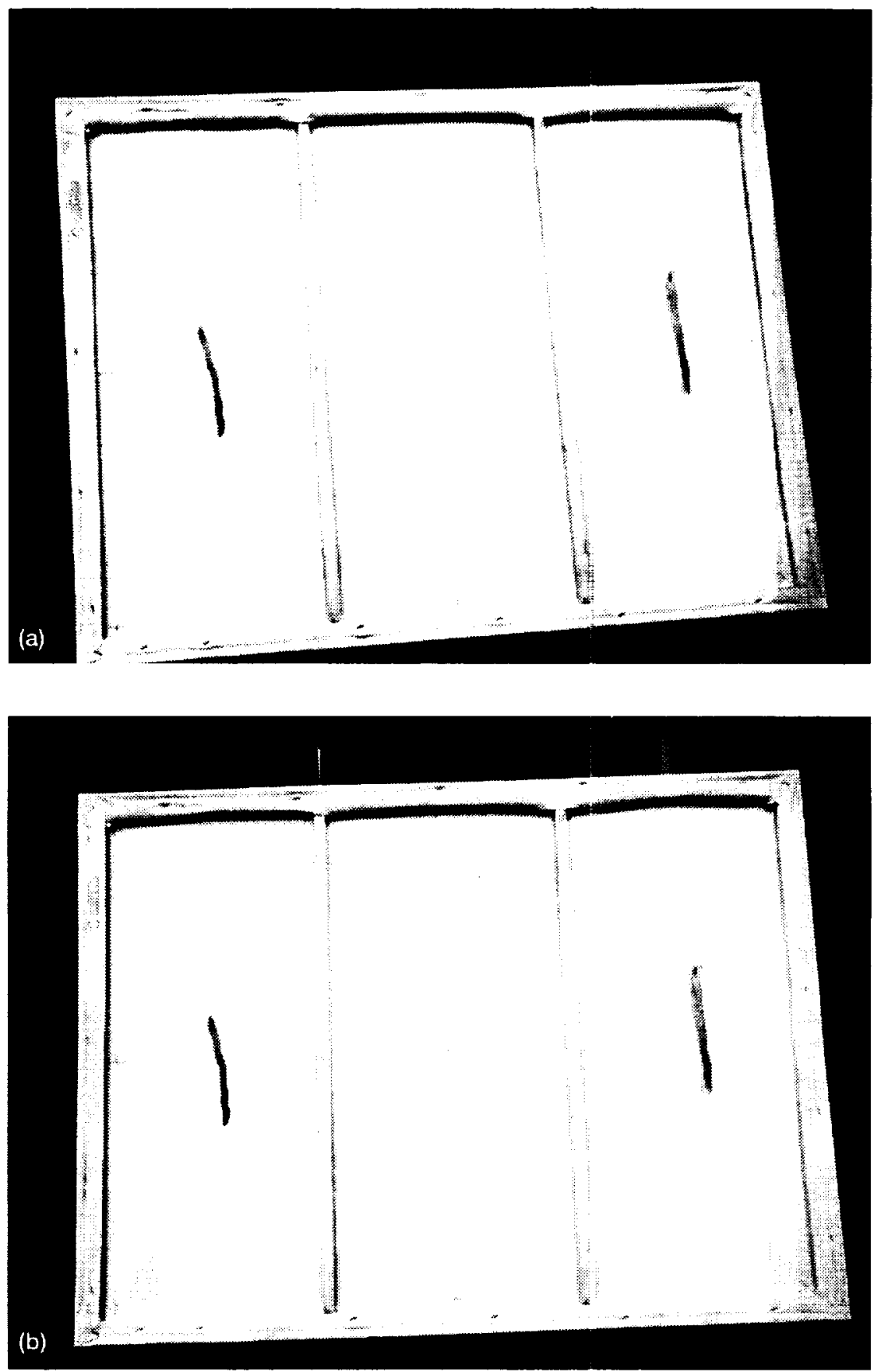

Figure 2.-Back side of the gesso showing candle soot streaks prior to (a) and after (b) cleaning with atomic oxygen (Back side was against the ground plate during cleaning allowing shielding to occur). 


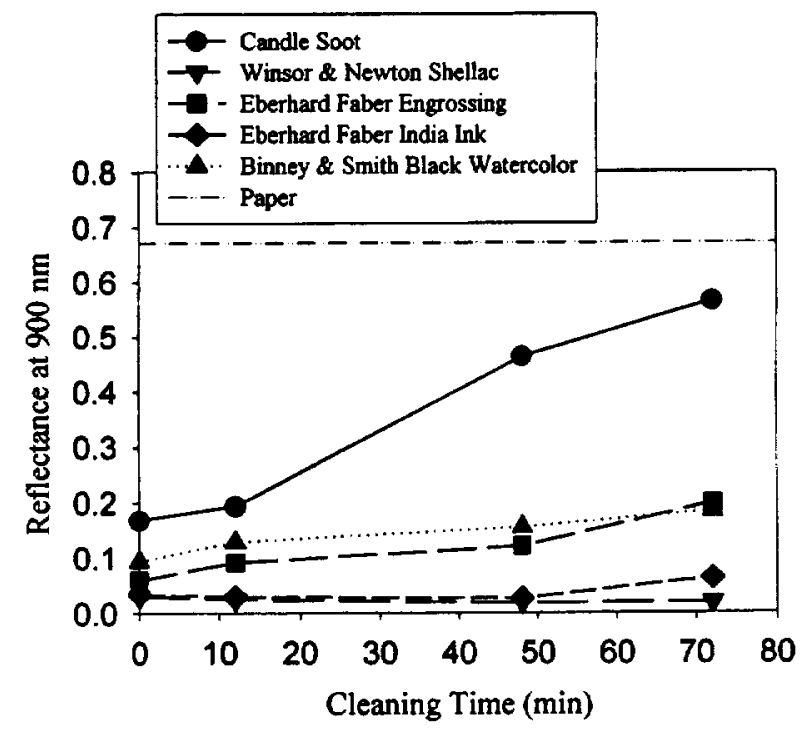

Figure 3.-Reflected light at $900 \mathrm{~nm}$ wavelength from the surface of soot and various inks as a function of atomic oxygen cleaning time.

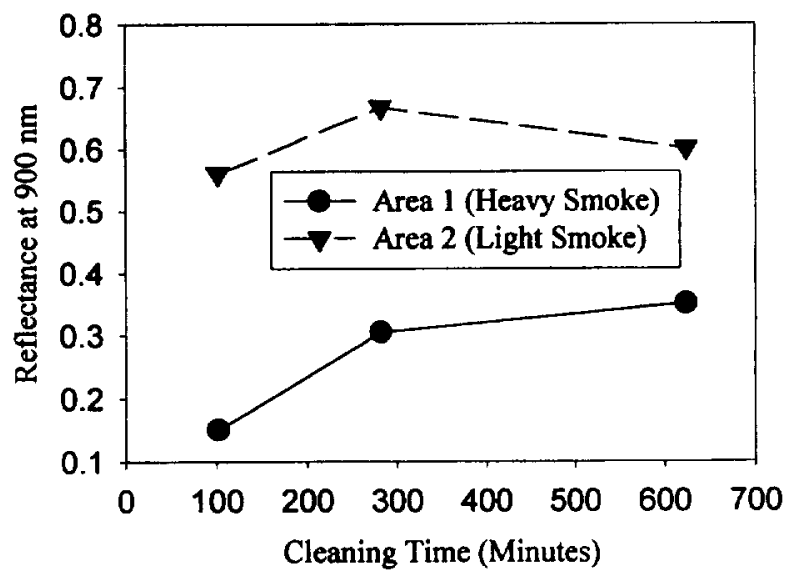

Figure 4.-Reflected light at $900 \mathrm{~nm}$ wavelength from the surface of light and dark smoked regions in the upper left comer of the Lichtenstein as a function of atomic oxygen cleaning time. 


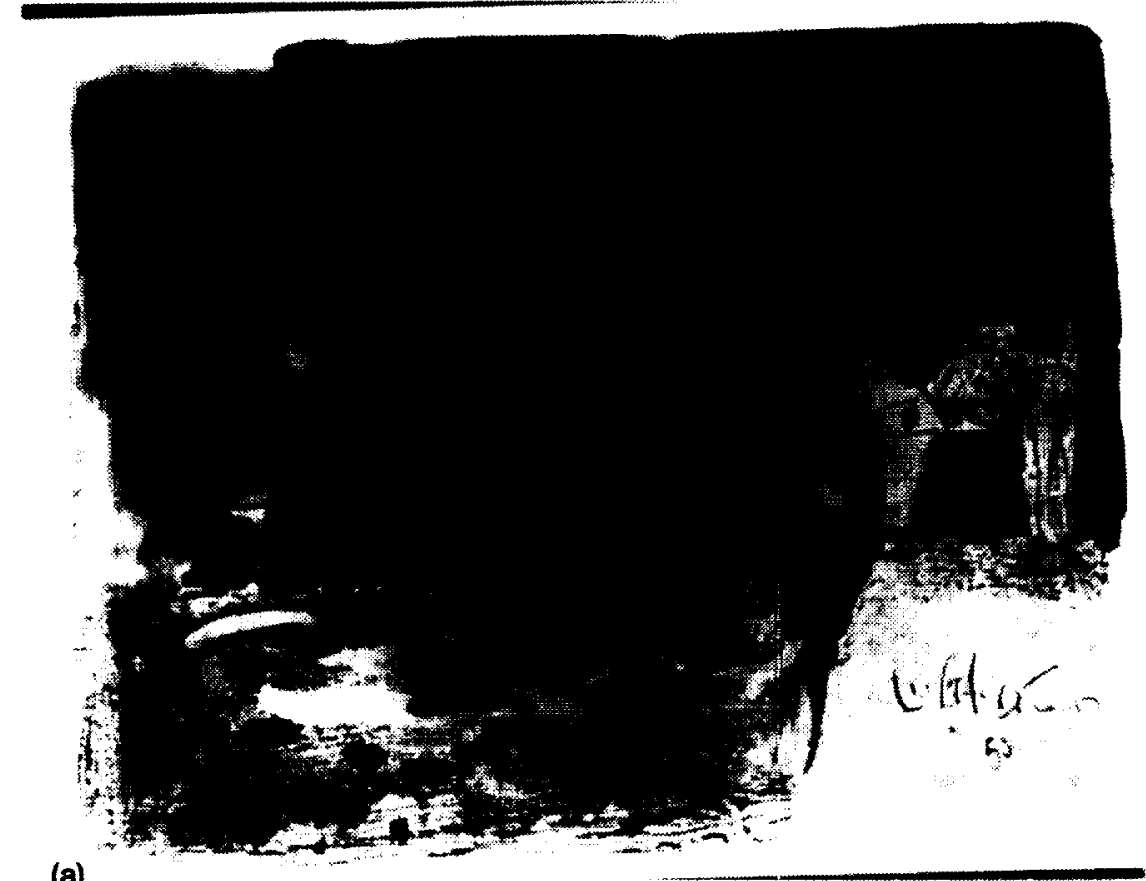

(a)

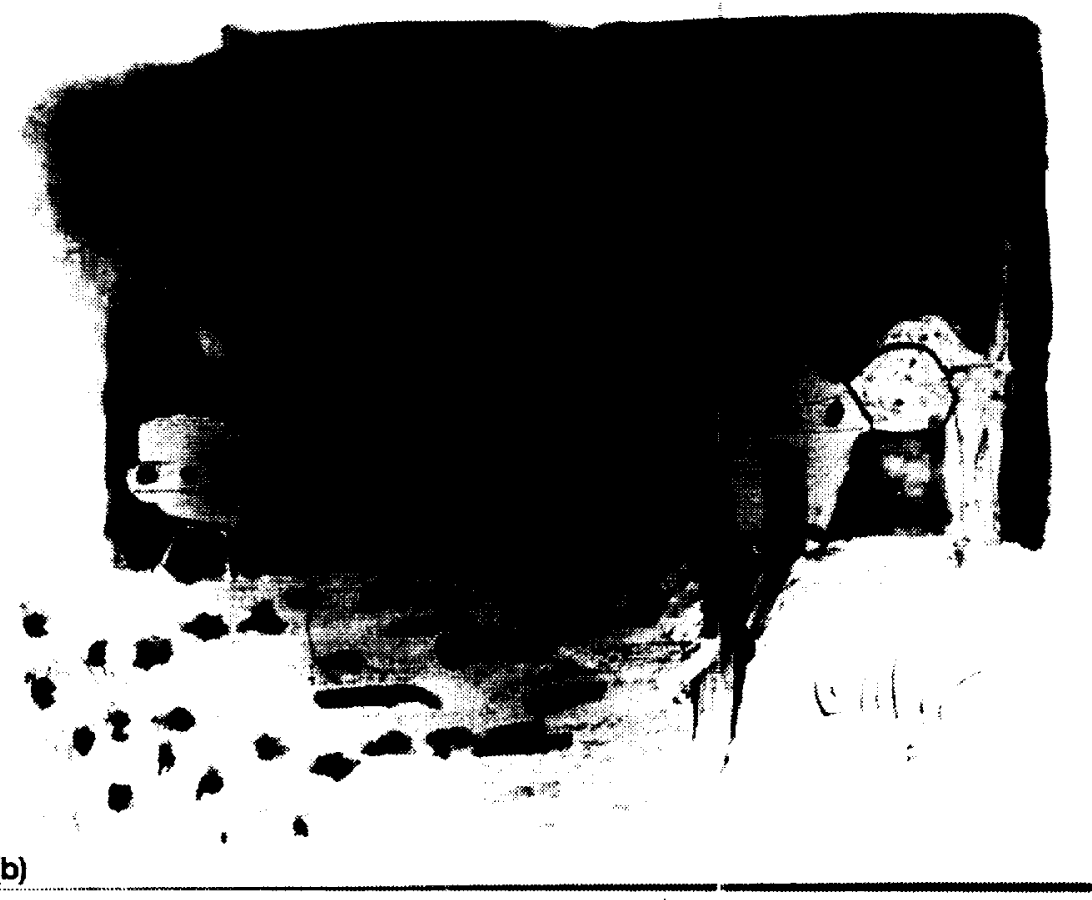

Figure 5-Lichtenstein untitled ink on paper prior tc (a) and after (b) cleaning with atomic oxygen. 


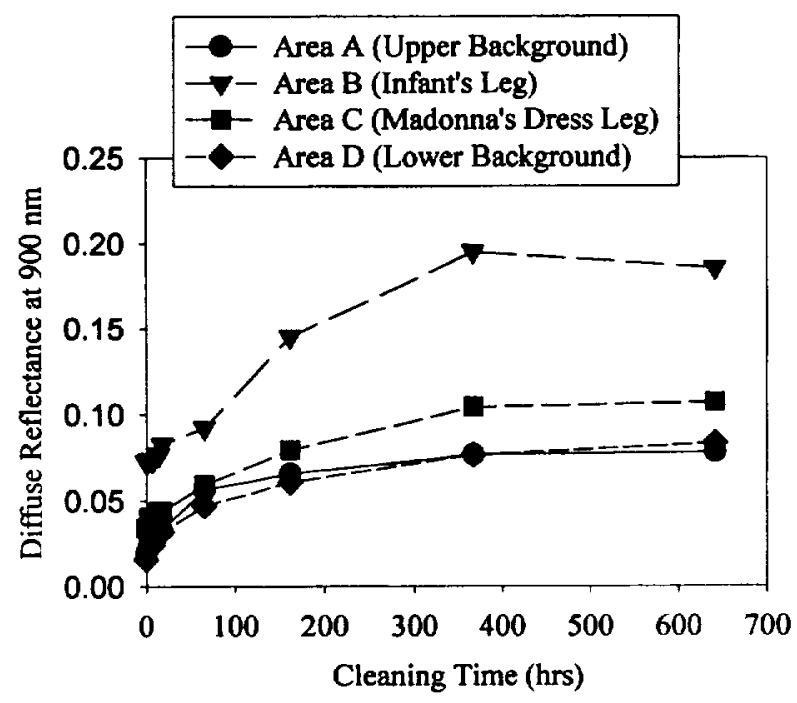

Figure 6.-Reflected light at $900 \mathrm{~nm}$ wavelength from selected areas of the Madonna of the Chair painting as a function of atomic oxygen cleaning time. 

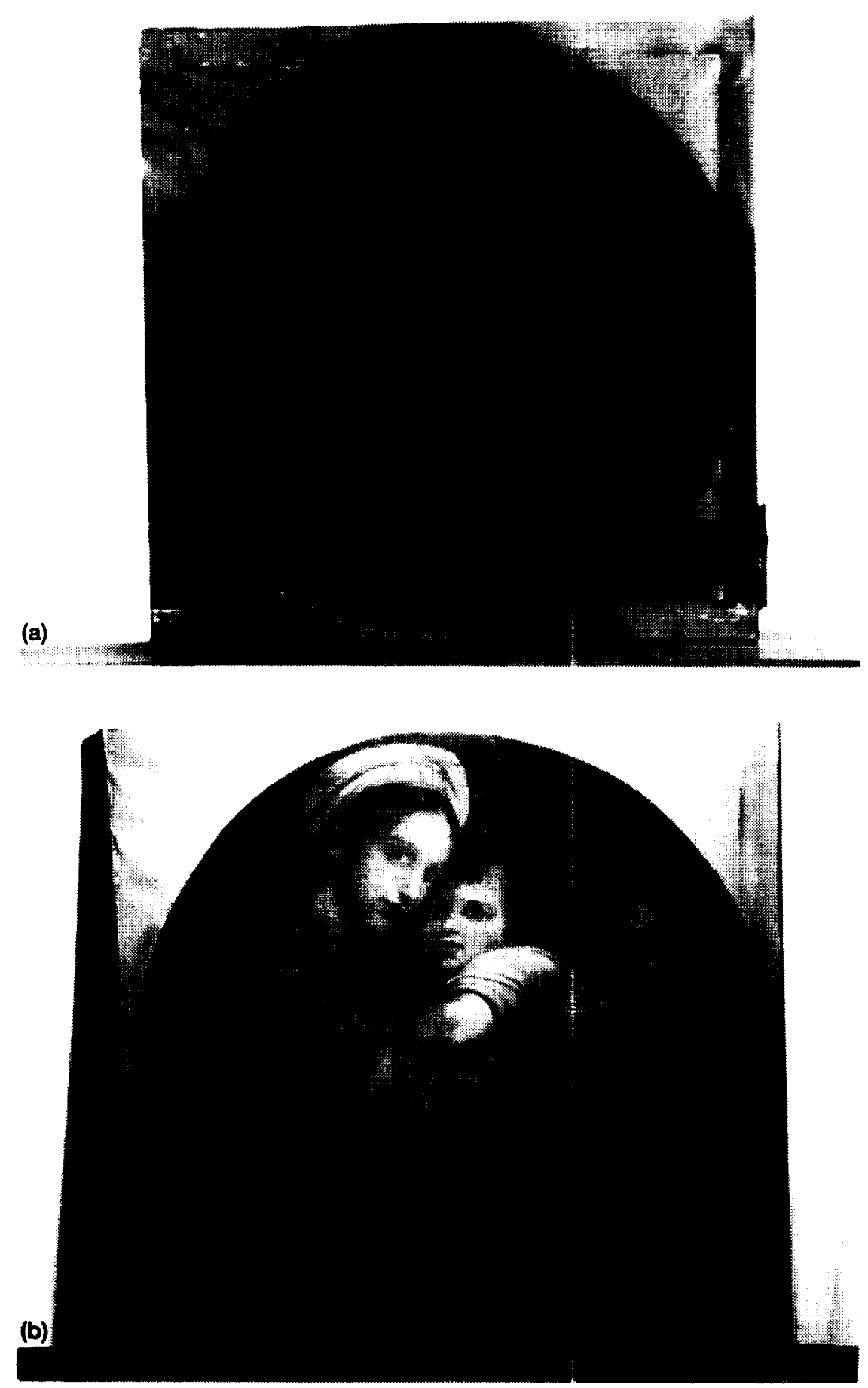

Figure 7.-Madonna of the Chair painting prior to (a) and after (b) cleaning with atomic oxygen. 
Public reporting burden for this collection of information is estimated to average 1 hour per response, including the time for reviewing instructions, searching existing data sources, gathering and maintaining the data needed, and completing and reviewing the collection of information. Send comments regarding this burden estimate or any other aspect of this Davis Highway, Suite 1204, Arlington, VA 22202-4302, and to the Office of Management and Budget, Paperwork Reduction Project (0704-0188), Washington, DC 20503.

\begin{tabular}{|l|l|l}
\hline 1. AGENCY USE ONLY (Leave blank) & $\begin{array}{c}\text { 2. REPORT DATE } \\
\text { September } 1998\end{array}$ & $\begin{array}{r}\text { 3. REPOAT TYPE AND DATES COVERED } \\
\text { Technical Memorandum }\end{array}$
\end{tabular}

4. TITLE AND SUBTTTLE

Atomic Oxygen Treatment as a Method of Recovering Smoke Damaged Paintings

6. AUTHOR(S)

Sharon K. Rutledge, Bruce A. Banks, Mark Forkapa, Thomas Stueber, Edward Seckhar, and Kevin Malinowski

\section{PERFORMING ORGANIZATION NAME(S) AND ADDRESS(ES)}

National Aeronautics and Space Administration

Lewis Research Center

Cleveland, Ohio 44135-3191

\section{SPONSORINGMONITORING AGENCY NAME(S) AND ADDRESS(ES)}

National Aeronautics and Space Administration

Washington, DC 20546-0001
WU-505-23-2C-00

8. PERFORMING ORGANIZATION REPORT NUMBER

E-11355

\section{SUPPLEMENTARY NOTES}

Prepared for the American Institute for Conservation of Historic Artwork sponsored by the American Institute for Conservation, Washington, DC, June 3-7, 1998. Sharon K. Rutledge and Bruce A. Banks, NASA Lewis Research Center; Mark Forkapa, Thomas Stueber, and Edward Seckhar, NYMA, Inc., 2001 Aerospace Parkway, Brook Park, Ohio 44142; Kevin Malinowski, Cleveland State University, Cleveland, Ohio 44115-2403. Responsible person, Sharon K. Rutledge, organization code 5480, (216) 433-2219.

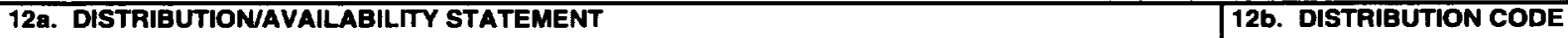

Unclassified - Unlimited

Subject Category: 23

Distribution: Nonstandard

This publication is available from the NASA Center for AeroSpace Information, (301) 621-0390.

\section{ABSTRACT (Maximum 200 words)}

Smoke damage, as a result of a fire, can be difficult to remove from some types of painting media without causing swelling, leaching or pigment movement or removal. A non-contact technique has been developed which can remove soot from the surface of a painting by use of a gently flowing gas containing atomic oxygen. The atomic oxygen chemically reacts with the soot on the surface creating gasses such as carbon monoxide and carbon dioxide which can be removed through the use of an exhaust system. The reaction is limited to the surface so that the process can be timed to stop when the paint layer is reached. Atomic oxygen is a primary component of the low Earth orbital environment, but can be generated on Earth through various methods. This paper will discuss the results of atomic oxygen treatment of soot exposed acrylic gesso, ink on paper, and a varnished oil painting. Reflectance measurements were used to characterize the surfaces before and after treatment.

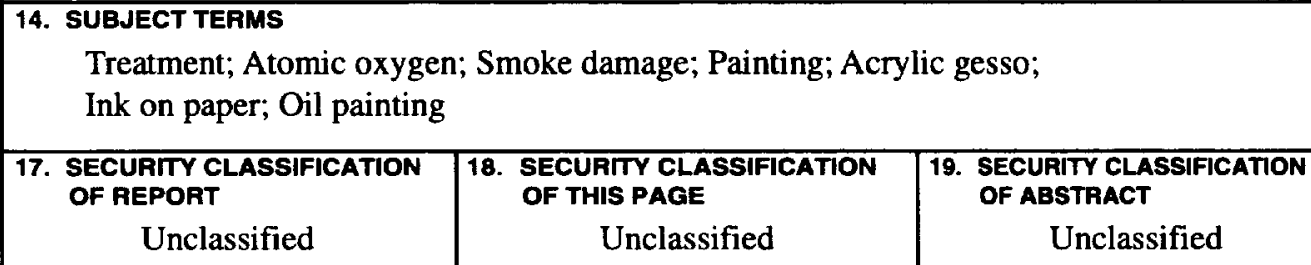

NSN 7540-01-280-5500
15. NUMBER OF PAGES 16. PRICE CODE

$\mathrm{AO3}$

20. LIMITATION OF ABSTRACT

20. LIMITATION OF ABSTRACT

Standard Form 298 (Rev. 2-89) Prescribed by ANSI Std. Z39-18 298-102 
